\title{
Vulnerability and social resilience: comparison of two neighborhoods in New Orleans after Hurricane Katrina
}

\author{
Jeanne Leroy ${ }^{1,3, a}$, Jim Amdal ${ }^{2}$, Marc Vuillet ${ }^{1}$, Jean-Marie Cariolet ${ }^{1}$, Youssef Diab ${ }^{1}$, and Vincent Becue ${ }^{3}$ \\ ${ }^{1}$ Ecole des Ingénieurs de la Ville de Paris, Lab'Urba, 80 rue Rebeval, 75019 Paris, France \\ ${ }^{2}$ University of New Orleans, Transportation Institute, 368 Minelburg Hall, 2000 Lakeshore Dr, New Orleans, LA 70148, USA \\ ${ }^{3}$ Université de Mons, Faculté d'Architecture et d'Urbanisme, rue d'Havré, 88, 7000 Mons, Belgique
}

\begin{abstract}
On August 29th of 2005, Hurricane Katrina hit the gulf coast of the United States leading to one of the most powerful disasters in history. Damage costs reached more than 100 billion dollars, as well as 150,000 flooded houses and 1,330 deaths. 10 years later, the damage remains visible in the city of New Orleans, and the rate of recovery is highly varied throughout different neighborhoods in the city. A popular idea is to associate this to the neighborhood social class, i.e. the poorer an area is, the more difficult the recovery process is. However the reality is more complex. This study looks at two economically similar and highly damaged neighborhoods, with two deeply different recoveries. The Lower 9th Ward, an isolated, and poor neighborhood surrounded by water with the Mississippi River and the industrial canal, has experienced an extremely slow recovery. However, in the isolated and relatively poor neighborhood known as Village de l'Est, located on former marshes at the edge of the city between Lake Pontchartrain and the Bayou Bienvenue, the Vietnamese community ties and cohesion have brought the neighborhood back to fruition faster than anyone would have expected. Despite many common features weakening their technical resilience, such as relatively modern and fast urbanization on former natural and low lands protected mostly by levees, their radically different reaction following Katrina points out the key role of social resilience. This communication will aim to present decisive social aspects of resilience aside from geophysical and physical features such as risk awareness, social link and community culture.
\end{abstract}

\footnotetext{
${ }^{\text {a }}$ Corresponding author: j.leroy@eivp-paris.fr
} 


\section{Introduction}

\subsection{Observations}

This article is the beginning of a $\mathrm{PhD}$ thesis reflection, and is based on several observations. First of all, despite the ongoing evolution of risk and crisis management, there are no cities fully protected from catastrophic events [1]. This has been illustrated by recent disasters such as the category 4 typhoon, Melor, which killed 45 persons in the Philippines as recently as December 2015, and the latest flood events hitting the South of France in October 2015, costing over 600 million euros and taking the live of 20 persons. Based on this assessment, cities are changing and trying to move forward with more hazard-concerned politics.

In the context of flooding, which is the focus of this article, it appears that technical protection measures are preferred by developed countries as they are considered reliable [2]. In the city of New Orleans, USA, well known for the phenomenal amount of hurricanes it has endured, the city flood protection system today is mainly based on flood walls, levees, canals and pumping stations [3]. This attraction to technology applies also in other parts of the world, such as France where technical measures to reduce flood hazards (rising levees and floodwalls, slowing down water flows...) represent more than $80 \%$ of the flood protection budget ${ }^{1}$ [4].

However, technical protection measures are not fully reliable, as demonstrated by recent disasters like Hurricane Katrina in 2005 and the European storm Xynthia in 2010, where some levees broke flooding large and supposedly "safe" urban areas. What is interesting to notice in these disasters is that on the one hand the technical protections failed, and on the other hand, the lack of the population's risk awareness and risk culture made it worse. Indeed, cities had to face not only the water's behavior but also the inhabitants' behavior, and the latter is as important and can be as surprising. For example, residents of the coastal city La Faute sur Mer on the west coast of France, got stuck and drowned in their own house after closing down the electric roller shades during the storm Xynthia, without realizing that they would not be able to open them again once the area is flooded and the power shut down. Similar accidents occurred with residents trying to reach their cars parked in underground parking structures, and could not make it back up to the surface because of the flooding. These kind of accidents show the importance of working on and with the people to improve flood and crisis management, as well as keeping up with technical protection measures.

Moreover, a community's cohesion can make the disaster less of a crisis and speed up the recovery process, which

\footnotetext{
${ }^{1}$ The flood protection budget is considered the budget granted through the action programs named PAPI (Programme d'actions de prévention des inondations) funded by the state, the regional and local governments, in order for the local governments to undertake measures against flood risk.
}

was the case of the Vietnamese Community of Village de l'Est in New Orleans after hurricane Katrina [5].

These observations bring us to the following scientific questions, that will be addresses in this article:

- How to define social resilience as opposed to technical resilience?

- Are there key aspects of social resilience?

- To what extent can social resilience excel in spite of technical vulnerabilities?

\subsection{Risk management, vulnerability and resilience}

Cities' reactions to hazards depend on their risk unique management approach. The United Nations define disaster risk management as « the systematic process of using administrative directives, organizations, and operational skills and capacities to implement strategies, policies and improved coping capacities in order to lessen the adverse impacts of hazards and the possibility of disaster. » [6]. Initially, risk management relied on the concepts of vulnerability and hazards, where vulnerability can be defined as «the characteristics and circumstances of a community, system or asset that make it susceptible to the damaging effects of a hazard. » [6].

Today, resilience is the conceptual framework for disaster risk management. Resilience comes from the latin resalire which refers to the idea of resisting and rebounding. It was originally used in physics to define to what extent a component could return to its initial state after being affected by an alteration. Then in 1970 through Holling's works in ecology, this concept became broader and could be defined as the amount of disruptions tolerated by a system while still functioning [7]. Resilience is not related to the ability to come back to a system's initial state, but to get back to a balanced state, even if it differs from the original. Pimm's vision [8] came a decade later and added the notion of time to resilience. The faster a system gets back to a balanced state after an event, the more resilient it is.

More recently, the international research network Resilience Alliance [9] gathered different aspects of resilience to establish the following definition on which this article is based. Resilience relies on (1) how much change can the system endure while keeping its functions intact; (2) the degree of the system's self-organization; and (3) the system's capacity to learn from the past and adapt. More than the amount of disturbance the system can tolerate, resilience also takes into account the way the system reacts - to what extent the system reacts by itself through self organization -, and the way the system will react in the future - depending on how the system adapts and finds a more sustainable balanced state.

For the last 15 years resilience has been developed with regards to cities as "urban resilience'. Indeed, cities can be considered as systems and therefore the resilience concept applies to them [7]. A resilient city is able to run in a reduced capacity and maintain its main functions even when some of its features are disrupted [10,11]. The city's functions rely on both the technical components and the social life, which brings us to 
Godschalk's definition of a resilient city as " a sustainable network of physical systems and human communities", [1, p.137].

\subsection{What we could define as technical resilience}

Vasu [12] gives a non-exhaustive list of the components of what we could call technical resilience, ranging from risk assessment to investment in equipment. In the context of flooding, technical resilience includes the natural environment's features such as location, situation, ground elevation, erosion susceptibility etc. But technical resilience is not limited to natural features, it also includes handmade-infrastructures and actions such as raising levees, digging drainage canals, altering the water flow and speed, building houses on stilts, raising structures, consolidating networks by repeating them etc. These components rely on officials' responsibilities (city, state, country), and are the main measures implemented in "traditional hazard mitigation", [1, p.139].

These measures are considered structural, as opposed to non-structural. A structural measure ranges from "any physical construction to reduce or avoid possible impacts of hazards, or application of engineering techniques to achieve hazard- resistance and resilience in structures or systems", [6].

It is important to note that technical resilience is not the result of a linear sum of all the components, but the interactions of one or more with another "to contribute to the overall resilience of a city in a symbiotic manner", [12]. Indeed, it would be naive to try to define the best technical resilience feature, as "all parts play a role, some play a more important than others dependent upon context and each part supplements one another" [12].

\subsection{What we could define as social resilience}

\subsubsection{Global idea and individual resilience}

The global idea behind social resilience is more ethereal [12]. In his study about social resilience in Singapore, Vasu defines it as "the ability of a nation to maintain social cohesion after the experience of a severe trauma", [12]. In the same way as technical resilience demonstrates, there are many components in social resilience and the idea is to develop them within the flood context. It is impossible to be exhaustive as an infinite number of components have impacts on social resilience, but we will present what we consider as the main ones in the context of urban flooding.

The concept of social resilience, social referring to society/human beings, results in the evolution of the concept of resilience in psychology. Boris Cyrulnik led this effort in the late nineties. He popularized this concept from John Bowlby's study about child/mother relation in the eighties. No matter his or her age, a resilient individual presented the following characteristics: high I.Q., autonomy, understanding of the environment, awareness of his or her personal value, relationship abilities and empathy, foreseeing and planning capacities, and humor [13]. Indeed, individual resilience could be defined as a set of qualities that gives a person the ability to overcome life-suffering events, or to stray from them. As explained by Anaut [14] a resilient individual could be compared to Batman, as opposed to Superman, since Batman doesn't have superpowers but he is smart and strong and able to adapt to any situation. In the same way, there are no needs for superpowers to be resilient.

\subsubsection{Community and societal resilience}

In the hazard context, not only individuals but groups too are to be looked at, as they are the essence of society and can be observed in cities. Psychologist Poirier points out four different scales of social resilience [15]: individual, family, community and society. We can notice the importance of the others in resilience as three out of the four scales listed above rely on the others, which highlights the crucial role of links and interactions between individuals. Cyrulnik ${ }^{2}$ asserts that loneliness is the best way to prevent resilience. In a world where humans don't live in a bestial way but in society, i.e. together, and often in cities, there is a need to look into the variety of group-related resilience scales to tackle the flood risk at the city scale. In this article, we decided to go deeper into the community and society resiliences as they occur outside of the household, leaving the family resilience for further research.

Lévy and Lussault [16] define community as a group of persons with conditional, voluntary and reversible solidarity, such as a neighborhood or a local society, and a society as the sum of elements that forms a nonreducible whole, and functions as a system. These two entities reflect individuals' gatherings and their interactions, whose consequences will impact individuals as well as the group globally. The following table lists some of the main resilience features at the community and the society levels, according to Poirier [15].

\begin{tabular}{|c|c|}
\hline Community resilience's factors & Society resilience's factors \\
\hline $\begin{array}{ll}\circ & \text { Solidarity } \\
\circ & \text { High expectations } \\
\circ & \text { Opportunities to get involved } \\
\circ & \text { Diversity of sources to get } \\
\text { support and resources } \\
\circ & \text { Low unemployment rate } \\
\circ & \text { Low crime rate } \\
\circ & \text { High level services (health, } \\
\text { education, housing, safety, } \\
\text { recreation, and transportation) }\end{array}$ & $\begin{array}{ll}\circ & \text { Mutual assistance and } \\
\text { social tolerance values } \\
\circ & \text { High expectations } \\
\circ & \text { Opportunities } \\
\circ & \text { Social and political norms } \\
\text { to fight poverty } \\
\circ \text { Strict gun control } \\
\circ \text { Strict drug and alcohol } \\
\text { policies } \\
\circ \quad \begin{array}{l}\text { Non-violent messages held } \\
\text { by media }\end{array}\end{array}$ \\
\hline
\end{tabular}

Figure 1: Resilience features at the community and the society levels, according to Poirier. Source: [21]. Conception: J. Leroy

\footnotetext{
2 Quote extracted from Boris Cyrulnik's speech in the French video «Le principe de résilience» (The resilience principle), uploaded on February 2nd, 2011, by WeeLearn on Youtube. Link to the video:
}

https://www.youtube.com/watch?v=oV3T55KmGE4. 
Interdependencies between the group and the individuals are found in the resilience's features presented above. Indeed solidarity, involvement and mutual assistance are crucial to flood resilience and come from exchanges within the population/community/society. Moreover, it is interesting to notice that resilience also relies on the city's services and urban system such as housing and transportation. Community and society scales are even more intriguing relative to resilience, as according to Hutter and his colleagues [17], a community's resilience doesn't simply match the sum of individuals' resilience. Individual depends on group, and vice versa.

As this article focuses on the flood risk, we will pay high attention to the following components: risk memory, risk awareness, risk perception, risk representation, risk culture, and good practices, in order to highlight the diversity and complexity of social resilience. They affect both levels: individual and group.

\subsubsection{Risk memory and risk awareness}

One important component of social resilience consists of being aware of the risk in order to lessen the surprise when the hazard comes, and thus to enhance the ability to face the event in a rational manner. Awareness is necessary because there is no way to fully eliminate the risk [18]. All the measures undertaken can only shrink the risk even though it will always exist.

In order to raise this awareness, one key aspect is to remember the past catastrophic events [19]. According to Labeur [19], the flood risk memory can be broken down into 4 components: (1) past significant events' references, (2) comparison and ranking of them (ordinary or exceptional), (3) the man-memory (memories from people who experienced flood events and told the stories to the next generations, refers to the "shared memories" notion developed by Margalit [20]), and (4) the current citizen-memory (memories experienced directly by the individual throughout his or her lifetime, refers to the "mutual memories" notion developed by Margalit [20]).

Indeed, flood risk memory consists of primarily in referring to significant former events. Therefore, the main challenge lies in the individual's ability to be aware of a risk that is surely going to happen again, but has not happened in his or her lifetime yet, and might not happen during his or her lifetime at all. Labeur [19] states that memory comes mostly from experience. However, when there is not a personal experience, experience can be taken from others, from relatives or social networks, including the neighborhood.

Approaching risk management through the memory lens is justified by the way the relation between local societies and danger is built. It develops through a dynamic game between memory and memory lapse, fear and denial [21]. Risk memory can be emphasized when materialized [22]. Common ways to materialize floods are flood marks and prints: flood marks can be official landmarks as well as paint lines on buildings for example, they are created after the flood event; flood prints consist in untouched marks left by the event, such as moisture lines or rescue tags on buildings. Flood events can also be materialized by places dedicated to the event such as memorials. Not only the presence of an object can bring back past event memories, its absence can do it too [23], for example looking at an empty lot where a house once stood.

\subsubsection{Risk perception and risk representation}

From the risk memory, coupled with risk awareness, individuals and groups establish a certain perception and representation of the risk. Risk perception refers to individual's and group's attitudes and opinions towards a given risk [24]. There is a possible denial of the flood risk by inhabitants. Indeed, they tend to consider their home as safe, and therefore to minimize, even deny, the existence of a danger that would make their home insecure [25]. Moreover, the more the residents get emotionally attached to a space, the more they feel safe in it, thus the less they perceive the risk as a threat, even though they know it still exists [26].

Representation doesn't only refer to a picture in its iconographic meaning, but to the individual or collective mental acts of projecting the future, and the projections are prone to change overtime [27]. Therefore, the risk and danger representations will have consequences on individuals and groups' adaptation behaviors and capacities [25], which bring us to the notion of risk culture notion.

\subsubsection{Risk culture and best practices}

Risk culture can be defined as the sum of risk awareness (through risk memory, itself changed by our perceptions and representations) and best practices [18]. Risk culture is more than risk awareness in that it includes knowledge of the risk and knowledge of the behaviors to follow in case of emergency and in the aftermath. Indeed, what we see and experience change the way we act, but is not enough to create a "risk culture" [28]. There is a need for an informative and learning process too, in order to strengthen resilience towards disasters. This process is still under construction, there is not a specific methodology to develop risk culture currently.

In the context of flooding, risk culture embraces different best practices such as acquiring flood insurance, keeping important papers safe, planning evacuations for yourself and your family, etc. It covers behaviors to follow before, during and after the crisis in order to endure it in the best way possible.

\subsection{Interests and goals}

This article presents a wide diversity of features that all interact with each other and are related to: the physical environment, the individual, the group, and their attitudes towards the flood risk. Studies and discussions to optimize disaster risk management are often divided between the technical and the social aspects, where it is known that these two are related and of equal importance 
[29-31]. Moreover, programs in hazard mitigation tend to focus more on raising physical systems' resistance towards disasters [1] as opposed to giving interest to social resilience. This preference is understandable as physical system's failures lead to immediate injury and damages [1]. However, social communities' awareness and behaviors should be part of future mitigation programs as "they will be the ones most responsible for building ultimate urban resilience", [1, p.137]. We will use the example of two New Orleans neighborhoods to investigate this idea and discuss the interdependency of social and technical resilience in the context of flooding.

\section{Two New Orleans neighborhoods in the aftermath of Hurricane Katrina}

\subsection{Hurricane Katrina and the flood protection system in New Orleans}

On August $29^{\text {th }}$ of 2005 , Hurricane Katrina hit the gulf coast of the United States leading to one of the most powerful disasters in history. Damage costs reached more than 108 billion dollars, as well as 150,000 flooded houses and 1,833 deaths ${ }^{3}$. New Orleans is an interesting case study as it makes it possible to compare the evolution of different neighborhoods after one identical extreme event, such as hurricane Katrina.

Moreover, New Orleans is a good example of a city "trusting'" technologies for its flood protections. In 1955, the U.S. Army Corps of Engineers were ordered by Congress to undertake a National Hurricane Research Project in collaboration with the U.S. Weather Bureau, to " assess the risk from future storms and the types of defenses that could be built to protect communities", [32]. A few years later in 1959, the Standard Project Hurricane was born. The project's aim of hurricane protection consisted of raising levees and building floodwalls and the total system was expected to protect communities from a 200-year storm. Right after hurricane Betsy in 1965, Congress passed a bill to establish the Lake Ponchartrain and Vicinity (New Orleans area) Hurricane Protection Project. In harmony with the national model, this project was mostly designed to tackle hurricane risk by improving physical protection measures. The map below illustrates the levees and floodwalls before hurricane Katrina.

${ }^{3}$ Data from National Weather Service of the United States. http://www.srh.noaa.gov/lix/?n=katrina_anniversary\#Impact

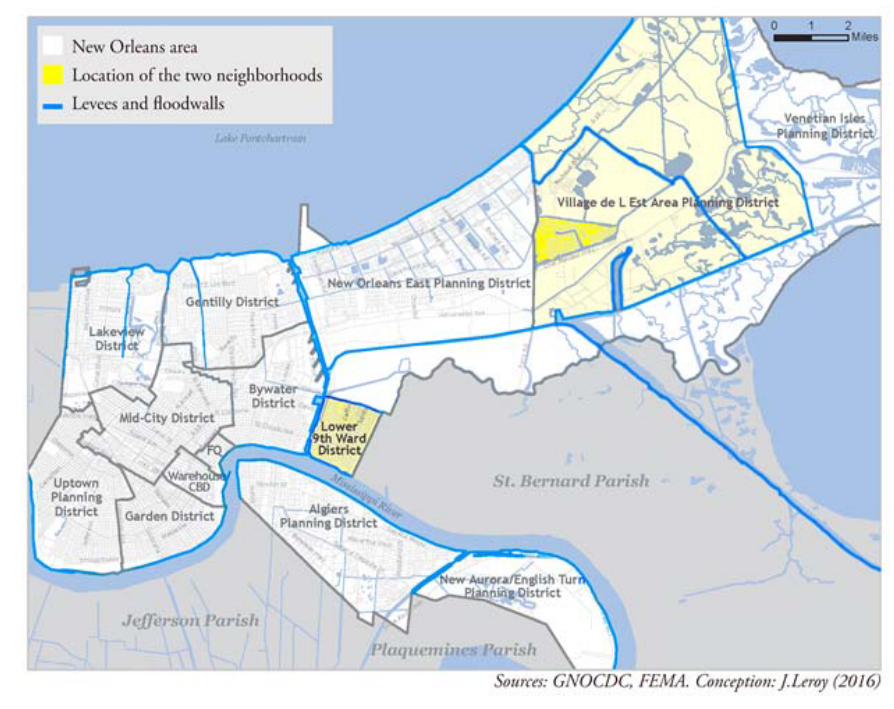

Figure 2: Levees and floodwalls in New Orleans before hurricane Katrina, and location of the neighborhoods studied.

New Orleans is also a good example of engineering failure since the protection system broke in over 50 locations whose failures created the disaster that followed the 2005 storms. The levees and floodwalls broke, flooding more than $80 \%$ of the city. This incident underlines how technological solutions are not fully reliable, despite our preference for them.

Hurricane Katrina started as an extreme weather event and was followed by a humanitarian crisis because of the United States government's failure to protect its citizens [33]. Leaving some residents stranded on their roofs or clustered in and around both the Superdome and the Morial Convention Center, these thirty thousand evacuees were without plumbing nor sufficient supplies for days. This situation pointed out extreme deficiencies in the City's evacuation plan. It failed miserably [34].

Despite many meetings, the reconstruction process to follow hurricane Katrina has not been planned [35]. Right after the storm, Mayor Nagin hired Wallace and Todd, a planning firm from Philadelphia, to devise a recovery plan. Together they led the efforts of the 'Bring New Orleans Back Commission (BNOBC)'. This team prepared several reports, the first one in November 2005, in order to redefine the urban footprint of the city. Part of the plan consisted of replacing former urbanized areas considered too vulnerable to flooding into green spaces (the infamous 'Green Dot' plan). However, due to extreme political pressure from residents recently returned from their exodus, the Mayor dismissed these plans and left the redevelopment up to the residents when they were allowed to come back to the city in the first week of October 2005, roughly six weeks after the storm [36].

During the years following the hurricane, the U.S. government funded the Road Home program to help Louisiana homeowners cope with the disaster. The program gave grants to homeowners through two different formulas: (1) stay and rebuild, and (2) sell and 
leave. It allowed many residents to return, but also made it more difficult for poorer neighborhoods homeowners, as the amount of the grant was calculated on the former houses' value instead of the actual cost of rebuilding, therefore they received less money than those from nicer neighborhoods.

Ten years after hurricane Katrina, the damage remains visible in the city of New Orleans, and the recovery rate has been highly varied throughout different neighborhoods. As opposed to some popular ideas, the poorest neighborhoods are not always the slowest to recover [37]. To highlight this statement, this article analyzes two economically similar and highly damaged New Orleans neighborhoods, with two deeply different recoveries: the Lower 9th Ward and the Village de l'Est.

\subsection{The Lower Ninth Ward}

\subsubsection{History, geography, vulnerabilities}

The Lower 9th Ward is an isolated and poor neighborhood surrounded on two sides by water: the Mississippi River and the Inner Harbor Navigation Canal (IHNC) (as shown on the map in part 2.1). The neighborhood was developed in the $1800 \mathrm{~s}$ in order to accommodate the growing population of New Orleans. Originally, the residents were middle class, but the situation deteriorated after the excavation of the industrial canal, which cut the neighborhood off from the rest of the city. The law abolishing slavery in the 1860 s and the damages caused by hurricane Besty in 1965, almost one century apart, also weakened this neighborhood. This led, on one hand, to an impoverishment of the neighborhood and a higher rate of crime, and on the other hand, to a more close-knit community [22]. Before hurricane Katrina, this mostly Afro-American neighborhood stood for having the highest rate of black homeowners in the state of Louisiana, $59 \%$ in $2000^{4}$.

The neighborhood is surrounded by water and protected by levees. It is divided in two areas, the older downriver of the IHNC and closest to the river known as Holy Cross, and the newer on lakeside of Saint Claude Avenue in the north known as the Lower Nine. Holy Cross lays on higher grounds at 60 to $90 \mathrm{~cm}$ above sea level while the Lower Nine sits at an average of $60 \mathrm{~cm}$ below sea level $^{5}$. It is a residential area, where most of the houses are one-floor buildings. Thus the Lower 9th Ward's vulnerabilities are physical as well as social.

\footnotetext{
${ }^{4}$ Data issued from The Data Center analysis of data from U.S. Census 2000 Summary File 1 (SF1) and U.S. Census 2010 Summary File 1 (SF1)

${ }^{5}$ Figures provided by Geographer Richard Campanella, Tulane University, in 2014. Full interview can be found p.58-64 in Leroy J., 2014, Etude de la viabilité des quartiers dans un contexte post-catastrophe: exemple du Lower 9th Ward à la Nouvelle-Orléans, Rapport de fin d'étude, 100p., Centre de documentation, EIVP.
}

\subsubsection{Hurricane Katrina, recovery and resilience}

The Lower 9th Ward was the most severely damaged neighborhood due to hurricane Katrina, more than 90\% of its residents lived in areas devastated by the storm [38]. After the hurricane, the Bring New Orleans Back Commission planned to convert part of the neighborhood into green spaces, which resulted in a viral outrage, and discrimination debates, since the most vulnerable areas of the city, which were the ones targeted to become green spaces, are often the poorest. Finally, the residents had to wait over a year for permission to come back, but could rebuild on the same lot their house occupied before Katrina.

The situation in the Lower 9th Ward was already difficult before the hurricane, but it became much worse after: roads and sidewalks were left damaged, only one "supermarket" remained which was a gas station providing only a few drinks and snacks, some schools did not reopen or were moved to other neighborhoods such as the Holy Cross School which relocated to Gentilly, the real estate market plummeted, and criminality went up, etc. The neighborhood suffered from a snowball effect: the lack of residents led to a lack of businesses and vice versa [39].

Several non-profit projects were created to boost the neighborhood's recovery but the results were moderate. Eco-friendly houses built on high stilts, designed by international architects and funded by the Make It Right Foundation are a good illustration. The project started in 2007 and built about 90 houses to help former residents from the Lower Ninth Ward return, but by 2012 the foundation decided to open-up to a larger group of applicants since too few former residents applied to purchase a house. Moreover, the futurist architecture styles did not really match with local needs and desires, which made it more difficult to find buyers [40]. Many non-profit organizations helped and are still helping residents rebuild their houses and others are developing gardens and orchards to provide free vegetables for the community and make use of empty lots.

The Lower Ninth Ward received incredibly high amount of media coverage and non-profit assistance with over ten thousand volunteers coming to help, tens of millions of dollars donated from foundations, and more than $\$ 600$ million from the city, state and federal governments [39]. However, a $72 \%\left(19,515\right.$ to $\left.5,556^{6}\right)$ population drop in between 2000 and 2010 occurred, displaying the lowest return rate of any neighborhood in the city of New Orleans ${ }^{7}$. Walking around the neighborhood today, flood prints and marks of the hurricane are everywhere: overgrown lots, empty lots, blighted houses, damaged

\footnotetext{
${ }^{6}$ Data issued from The Data Center analysis of data from U.S. Census 2000 Summary File 1 (SF1) and U.S. Census 2010 Summary File 1 (SF1)

${ }^{7}$ The New Orleans population varied from 484,674 in 2000 to 343,829 in 2010, being a 29\% drop (Data issued from the Data Center Analysis quoted in footnote number 5).
} 
roads and sidewalks, renovated houses still displaying the rescue tag, etc.

\subsection{Village de l'Est}

\subsubsection{History, geography, vulnerabilities}

The Village de l'Est is an isolated and relatively poor neighborhood located on former marshes at the eastern edge of the city between Lake Pontchartrain and Bayou Bienvenue (as shown on the map in part 2.1, the bright yellow area represents the area of the district, and the dark yellow represents the area of the neighborhood). The land is approximately 2.5 square $\mathrm{km}$ (600 acres) and was majorly developed in 1964 with single and double affordable houses, mostly ranch style. The population was mostly Afro-American but during the 1970s and 1980 s, thousands of Vietnamese immigrated to the area. This was the result of a political refugee camp opening in the eastern part of New Orleans following the Vietnam War. The first migration wave created a domino effect with the migration of refugees' families and friends, and by 1990 the Vietnamese community in New Orleans East was about 5,000 people [5]. The term community in this case has an ethnic connotation. Indeed, the Vietnamese and the Afro-American populations lived in the same neighborhood but were not part of the same community since they did not often interact with each other [5]. By 2000 , the population was a mix of both Vietnamese and Afro-American residents $(55.4 \%$ Black or African American and $37.1 \%$ Asian in $2000^{8}$ ). The neighborhood is working class, with a high poverty level, $29.9 \%$ in 2000 , twice as high as the average of the city.

One of the significant aspects of the Vietnamese community lies in its social organization. As soon as the Vietnamese arrived in New Orleans, they created a structured system similar to the one they had in Vietnam. It consisted of a religious and community life leader, in this case Priest Nguyen, who worked in partnership with a committee composed of representatives of the neighborhood. This committee makes essential decisions for the community, based on the representatives' testimonies.

Since it was built on a drained marshland, Village de l'Est possesses many physical vulnerabilities. Ground elevation is the lowest in all of New Orleans reaching to $2 \mathrm{~m}$ below sea level and it also suffers from subsidence problems. The neighborhood is at the eastern edge of the city, leaving only swamps beyond. Its existence was made possible by the city flood protection system thanks to drainage and pumping, and these engineering systems are also the ones protecting the neighborhood from flooding.

\subsubsection{Hurricane Katrina, recovery and resilience}

\footnotetext{
${ }^{8}$ The Data Center analysis of data from U.S. Census 2000 Summary File 1 (SF1) and U.S. Census 2010 Summary File 1 (SF1)
}

The Village de l'Est was largely flooded by hurricane Katrina, water came from every direction after the levees were overtopped or breached [41]. More than $1.8 \mathrm{~m}$ (6 feet) of water rushed into the neighborhood, damaging $91 \%$ of the occupied homes [42].

Soon after the hurricane, residents from the Vietnamese community started to come back, fast enough that when the Mayor authorized New Orleans residents to come back to the city, 600 residents of the Village de l'Est were already there, picking up the trash and starting to fix their houses [5]. The community managed to obtain dumpsters from the city in order to facilitate cleaning. They also got the electricity back by October 2005 thanks to a petition signed by current residents and former residents claiming they wanted to come back [5]. The solid organization developed by the community enabled them to be more efficient and stronger at both scales: within the community and in front of city officials.

Priest Nguyen took key actions to help in the recovery process: communications with the evacuees about their situations and the day-to-day situation in New Orleans, assistance for the elderly and the disabled for evacuation and for their return, management of neighborhood representatives' gatherings located in Houston postKatrina starting from October 2005 to plan for the residents' return.

The Village de l'Est received high media cover, highlighting its fast recovery ${ }^{9}$. By the spring 2007, more than $90 \%$ of the Vietnamese community was back in the neighborhood, where less than $50 \%$ of the Black Americans were. The neighborhood's population dropped from 12,912 in 2000 to 8,008 individuals in 2010, showing a $62 \%$ return rate. And the vacant housing units went from $4.6 \%$ in 2000 , to $14.9 \%$ in 2010 , a much lower number than the city wide average ${ }^{10}$.

\section{Discussion}

\subsection{Comparison of the neighborhoods' recovery}

The recovery process in the Lower Ninth Ward and the Vietnamese community of the Village de l'Est took different patterns. First, although their technical resilience was weak in both neighborhoods, their social resiliences were distinctly different. Both neighborhoods went through the same society resilience at the city scale, the difference occurred at the individual and the community scales. When comparing to Pottier's factors of resilience (cf. tab below), the major differences between the two neighborhoods at the community's scale

\footnotetext{
Examples of articles related to the Vietnamese community recovery:

http://www.npr.org/templates/story/story.php?storyId=9163113, http://www.npr.org/templates/story/story.php?storyId=5400944, http://transcripts.cnn.com/TRANSCRIPTS/0512/16/acd.02.html ${ }^{10}$ In 2010, New Orleans rate of vacant housing units was up to $25.1 \%$. More datas can be found in The Data Center analysis of data from U.S. Census 2000 Summary File 1 (SF1) and U.S. Census 2010 Summary File 1 (SF1).
} 
are the solidarity's level and organization, the reaction to the lack of opportunities to get involved, and the diversity of sources to get support and resources. It appears that the support and resources received by the Lower Ninth Ward were mostly exterior to the community. However, one aspect of resilience is the system's capacity for selforganization. This capacity was highly developed in the Vietnamese community thanks to its prior solid organization. This facilitated solidarity within the group, as opposed to the Lower Ninth Ward where solidarity existed but was harder to set up as there was no specific organization or competing organizations representing different groups.

Moreover, if both neighborhoods had the same opportunities to get involved in their return, the Village de l'Est created opportunities by acting within the neighborhood, and fighting for their ideas in front of officials at all levels of government. The community's cohesion and organization have brought the neighborhood back to fruition faster than anyone would have expected, and much faster than the Lower Ninth Ward.

\begin{tabular}{|l|c|c|}
\hline \multicolumn{1}{|c|}{$\begin{array}{c}\text { Community } \\
\text { resilience's factors }\end{array}$} & $\begin{array}{c}\text { Vietnamese } \\
\text { Wower Ninth } \\
\text { Ward Situation } \\
\text { Community of } \\
\text { the Village de } \\
\text { l'Est Situation }\end{array}$ \\
\hline Solidarity & Medium & $\begin{array}{c}\text { High and } \\
\text { organized }\end{array}$ \\
\hline High expectations & Yes & Yes \\
\hline $\begin{array}{l}\text { Opportunities to get } \\
\text { involved }\end{array}$ & No & Created them \\
\hline $\begin{array}{l}\text { Diversity of sources } \\
\text { to get support and } \\
\text { resources }\end{array}$ & $\begin{array}{c}\text { Non-profit } \\
\text { organizations } \\
\text { and officials }\end{array}$ & $\begin{array}{c}\text { Community and } \\
\text { officials }\end{array}$ \\
\hline $\begin{array}{l}\text { Low unemployed } \\
\text { rate }\end{array}$ & No & No \\
\hline Low crime rate & No & No \\
\hline $\begin{array}{l}\text { High level services } \\
\text { (health, education, } \\
\text { housing, safety, } \\
\text { recreation, and } \\
\text { transportation) }\end{array}$ & No & No \\
\hline
\end{tabular}

Figure 3: Resilience features at the community level in both neighborhoods

Moreover, it is interesting to notice that the Vietnamese community's cohesion was particularly significant for bringing residents back home; for the evacuation, community's members called on outside networks in order to find temporary housing. This behavior seems logical since the whole community was going through a crisis, and so there was a need for an outside assistance. Nonetheless it also highlights the none restrictions nor self-sufficiency of communities: being part of a community doe not mean interactions should only happen within the community; social network develops inside and outside of the community. Whenever the community is under crisis circumstances, which was the case when hurricane Katrina hit New Orleans, its members have to use their individual resilience and reach out to their personal network. Once the community gets some strength back, it can take over the individual scale, which points out the evolution of a resilience capacity overtime. It is a balance of roles and interactions that is constantly changing.

Finally, in this case study, in spite of a weak technical resilience, one neighborhood managed to recover from the disaster thanks to a high social resilience. However social resilience does not suppress the technical vulnerabilities. Indeed without the flood protection system, the former swamps of the Village de l'Est would not be livable. Social resilience does not replace technical resilience, it completes it in order to get through the future technical failures whose timing is unsure but existence is certain. Social and technical resiliences are not separate and stable entities, they depend on and interact with one another, as every component of urban resilience does.

\subsection{How are these results reusable in other parts of the world?}

This case study makes us think about the role social organization plays within a community and may be the key aspect of social resilience. However the community used in this case study presents a specific background that should not be overlooked. First of all, the Vietnamese community's social organization efficiency came from its solid and historical roots. The facility to create social bonds and relations within the community is the result of two parameters: geographical closeness by living in the same neighborhood, and common interest by believing in the same religion $(75 \%$ of the community members are Catholics [5]). It facilitated the establishment of a group leader, a key member of the group's organization. Such an organization might have been possible in another community without prior assets, even if it was possible, it would take longer to set up and when time is a critical factor in recovery.

Moreover, the Vietnamese community has a specific past, which played a crucial role in its recovery process. The community members are political refugees and fled a country under war with the United States. Leong and her colleagues [5] explain that residents testified how hurricane Katrina event was not as traumatic compared to what they went through in Vietnam during the war, and then when they decided to leave their country and culture, and abandoned everything they had to come to the United States. Thus, the example of this community underlines the importance of social cohesion and organization is also goes further, highlighting the role of adaption. As opposed to a specific flood risk culture, it is a larger culture that this community owns, that we could called adaptation culture. This capacity to adapt is maybe not the key but definitely $a$ key to resilience [43]. It conveys a larger capacity than the possibility to recover from a specific event such as flood. Adaptation enables to 
overcome uncertainty. As Vasu states in his study about Singapore [12, p.6], "perhaps key to operating successfully involves an alteration of mindset where one is comfortable with living and acting under conditions of uncertainty'".

\subsection{Is resilience always beneficial?}

Resilience is often defined and seen as a positive capacity. After questioning and understanding better this concept through this case study, it is interesting to question in what extent is this capacity beneficial. For example, in the New Orleans case study, community resilience enabled residents to "get their life back" but we can wonder what was the most resilient decision between planning the rebuilding of the city by redefining the footprint limits, and letting the residents free to rebuild on the exact same lots they were on before the hurricane? Both can be qualified as resilient, but resilient for whom and in what timeframe? The idea of resilience is to get back to a balance state, a better one when possible. However, quick decisions such as the ones taken about the rebuilding plans in New Orleans can make it better for the communities in the short term, and worse in the long term. The goal of the two neighborhoods' residents studied is to get back to an identical state, not a better one. When the goal of the city's officials was to bring the city to a better and safer state. Which shows that resilience at one scale can be seen as injustice at another scale [37]. Consequently it appears to be fairer for residents to rebuild the city as they knew it in order to come back to the city but also to the exact same neighborhood and lot they were living on before the storm. If on a technical point of view, going back to an identical state makes the situation worse, as the physical vulnerabilities still exist and won't get better; on a social side, this identical state permits the returnees to recreate social bonds easily and so increase social resilience in the long term [37].

Moreover, resilience does not apply to positive social networks only; it applies to any kind of system including criminal networks and poverty. This is what Hernandez [37] called toxic resilience, and according to Rufat [44], informal systems are the ones the most subject to resilience. This does not mean resilience is not a valuable capacity to emphasize in order to improve disasters recovery, but it should be considered with a wide lens, to understand each system's reaction no matter how toxic or beneficial it is for the city.

\section{References}

1. Godschalk D. R. (2003). Urban hazard mitigation: creating resilient cities. Natural Hazards Review, August, pp. 136-143

2. Terrin J-J. (sous la direction de) (2014). Villes inondables. Prévention, résilience, adaptation. Parenthèses, 288p.

3. Public Law 110-114-Nov. 8, 2007, 110th Congress, US Government
4. CEPRI (2007), Les PAPI six ans après leur démarrage. Rapport CEPRI, 4p.

5. Leong K. J., Airriess C. A., Li W., Chia-Chen Chen A. C., Keith V. M. (2007). Resilient History and the Rebuilding of a Community: The Vietnamese American Community in New orleans East. The Journal of American History, December, pp 770-779

6. United Nations Office for Disaster Risk Reduction UNISDR (2009). Terminology on Disaster Risk Reduction. 30p.

7. Pizzo B. (2015). Problematizing resilience : Implications for planning theory and practice, Cities, Vol. 43, pp.133-140

8. Pimm S. L. (1984). The complexity and stability of ecosystems, Nature, Vol. 307, pp. 321-326

9. Resilience Alliance, http:/www.resalliance.org

10. Toubin M., Lhomme S., Diab Y., Serre D., Laganier R. (2012). La résilience urbaine : un nouveau concept opérationnel vecteur de durabilité urbaine?, Développement durable et territoires, Vol. $3, \mathrm{n}^{\circ} 1$

11. Lhomme S., Serre D., Diab Y., Laganier R., (2013). Assessing resilience of urban networks : a preliminary step towards more flood resilient cities, Natural Hazards and Earth System Sciences, Special Issue: Natural hasard resilient cities, pp. 221-230

12. Vasu N. (2007). Social resilience in Singapore: reflections from the London bombings. Select Publishing, Singapore, 110p.

13. Cyrulnik B., (1998). Ces enfants qui tiennent le coup. Hommes et perspectives, 120p.

14. Anaut M. (2003). La résilience, Surmonter les traumatismes. Editions Nathan Université, 125p.

15. Poirier C. (2001). La Résilience. Présentation, the Psychologist at the Institut de Psychanalyse de Paris, Pavillon Roland Saucier

16. Lévy J. and Lussault M., (2013). Dictionnaire de la géographie et de l'espace des sociétés, Belin, 1127p.

17. Hutter G., Kuhlicke C., Glade T. and Felgentreef C. (2011). Natural hazards and resilience: exploring institutional and organizational dimensions of social resilience. Natural Hazards, Vol. 60, pp.1-6

18. Blesius J-C. (2013). Discours sur la culture du risque, entre approches négative et positive. Vers une éducation aux risques? Géographie et cultures, Vol. 88, pp. $249-265$

19. Labeur C. (2013). Raconter l'inondation : quand les récits de catastrophes se font mémoire du risque. Géocarrefour, Vol. 88, pp. 45-54

20. Margalit A. (2006). L'éthique du souvenir. Paris, Climats, 224p.

21. Langumier J. (2005). Genèse du risque et mémoire de la catastrophe: une approche ethnographique des inondations dans les Basses Plaines de l'Aude. Pour mémoire, Comité d'Histoire, n4, pp. 8-25 
22. Leroy J. (2014). Etude de la viabilité des quartiers dans un contexte post-catastrophe : Exemple du Lower 9th Ward à la Nouvelle-Orléans. Rapport de stage de fin d'étude, Ecole des Ingénieurs de la Ville de Paris, encadré par Amdal J.R, Senior research associate, University of New Orleans et Youssef Diab, professeur l'Université Paris Est, 100 p.

23. Garros-Levasseur E. (2015). Remembering and transmitting flooding experiences through material traces. Workshop Imagining the future of collective memory, Neuchâtel, June 4-5

24. Slovic P. (2000). The perception of risk. Risk, society, and policy series, Earthscan Publications, $473 p$.

25. Michel-Guillou E., Lalanne P-A., Krien N. (2015). Hommes et aléas: appréhension des risques côtiers par des usagers et des gestionnaires de communes littorales. Pratiques psychologiques, 21, pp. 35-53

26. Billig M. (2006). Is My Home My Castle? Place Attachment, Risk Perception, and Religious Faith. Environment and Behavior, Vol. 38, no. 2, pp. 248265

27. Coanus T., Duchêne F., Martinais E. (2004). Risque, territoire et longue durée: vers une "société du risque $»$ ? Les annales de la recherche urbaine, $\mathrm{n}^{\circ} 95$, Apprivoiser les catastrophes, pp.19-25

28. Theys J. (1987). La société vulnérable. In J.-L. Fabiani and J. Theys, La société vulnérable : évaluer et maîtriser les risques, Presses de l'École Normale Supérieure, Paris, pp. 3-36

29. Cutter S., Barnes L., Berry M., Burton C., Evans E., Tate E. and Webb J. (2008). Community and regional resilience : perspectives from hazards, disasters, and emergency management, CAPRI Research Report 1, Oak Ridge : Community and Regional Institute

30. Cutter S., Barnes L., Berry M., Burton C., Evans E., Tate E. and Webb J. (2008). A placed-based model for understanding community resilience to natural disasters. Global Environnement Change, Vol. 18, pp. 598-606

31. Cutter S., Burton C. and Emrich C. (2010). Disaster Resilience Indicators for Benchmarking Baseline Conditions. Journal of Homeland Security and Emergency Management, Vol. 7, article 51

32. The Lens (2014). New Orleans' flood protection system: Stronger than ever, weaker than it was supposed to be. By Bob Marshall, May 15

33. Walters J. (2015). A guide to Hurricane Katrina and Its Aftermath. Jacobin

34. Los Angeles Times (2005). Trapped in an Arena of Suffering, Sept 01, Scott Gold

35. Amdal J.R. (2013). Urban resilience in postKatrina/Rita in New Orleans. In Resilience and Urban Risk Management, directed by Serre, Barroca and Laganier, Taylor and Francis Group, London, 179p.
36. Zaninetti J-M. (2013). Adaptation urbaine postcatastrophe: la recomposition territoriale de la Nouvelle Orléans. Cybergeo : European Journal of Geography, Document 636

37. Hernandez J. (2012). Résilience contradictoires et résilience toxique dans la Nouvelle-Orléans postKatrina, in Résiliences urbaines, les villes face aux catastrophes, coordinated by Djament-Tran G. and Reghezza-Zitt M., Le Manuscrit, pp. 243-274

38. Logan R. L. (2006). The impact of Katrina: Race and Class in Storm Damaged Neighborhood. Spatial Structures in the Social Sciences, Brown University, Working paper

39. The Nation (2015). Why the Lower Ninth Ward looks like the Hurricane just hit. By Gary Rivlin, August 13

40. The Washington Post (2015). What happened when Brad pitt and his architects came to rebuild New Orleans. By Peter Whoriskey, August 28

41. The Times Picayunes (2015). Anatomy of a flood: How New Orleans flooded during Hurricane Katrina. By Dan Swenson, NOLA.com, August 12

42. Seidman K. F. (2013). Coming Home to New Orleans: Neighborhood Rebuilding After Katrina. Oxford University Press, 383p.

43. Poletti R. and Dobbs B. (2001). La résilience, l'art de rebondir. Jouvence, $94 p$.

44. Rufat S. (2012). Existe-il une «mauvaise» résilience? In Résiliences Urbaines, Les villes face aux catastrophes, Djament-Tran G., Reghezza-Zitt M. (eds), Éditions du Manuscrit, Fronts pionniers, pp. $195-242$ 